This item was submitted to Loughborough's Research Repository by the author.

Items in Figshare are protected by copyright, with all rights reserved, unless otherwise indicated.

\title{
Rethinking soft OR interventions: models as boundary objects
}

PLEASE CITE THE PUBLISHED VERSION

http://dx.doi.org/10.1016/j.ejor.2013.06.033

PUBLISHER

(c) Elsevier

VERSION

AM (Accepted Manuscript)

LICENCE

CC BY-NC-ND 4.0

REPOSITORY RECORD

Franco, L. Alberto. 2019. "Rethinking Soft OR Interventions: Models as Boundary Objects". figshare. https://hdl.handle.net/2134/14644. 
This item was submitted to Loughborough's Institutional Repository (https://dspace.lboro.ac.uk/) by the author and is made available under the following Creative Commons Licence conditions.

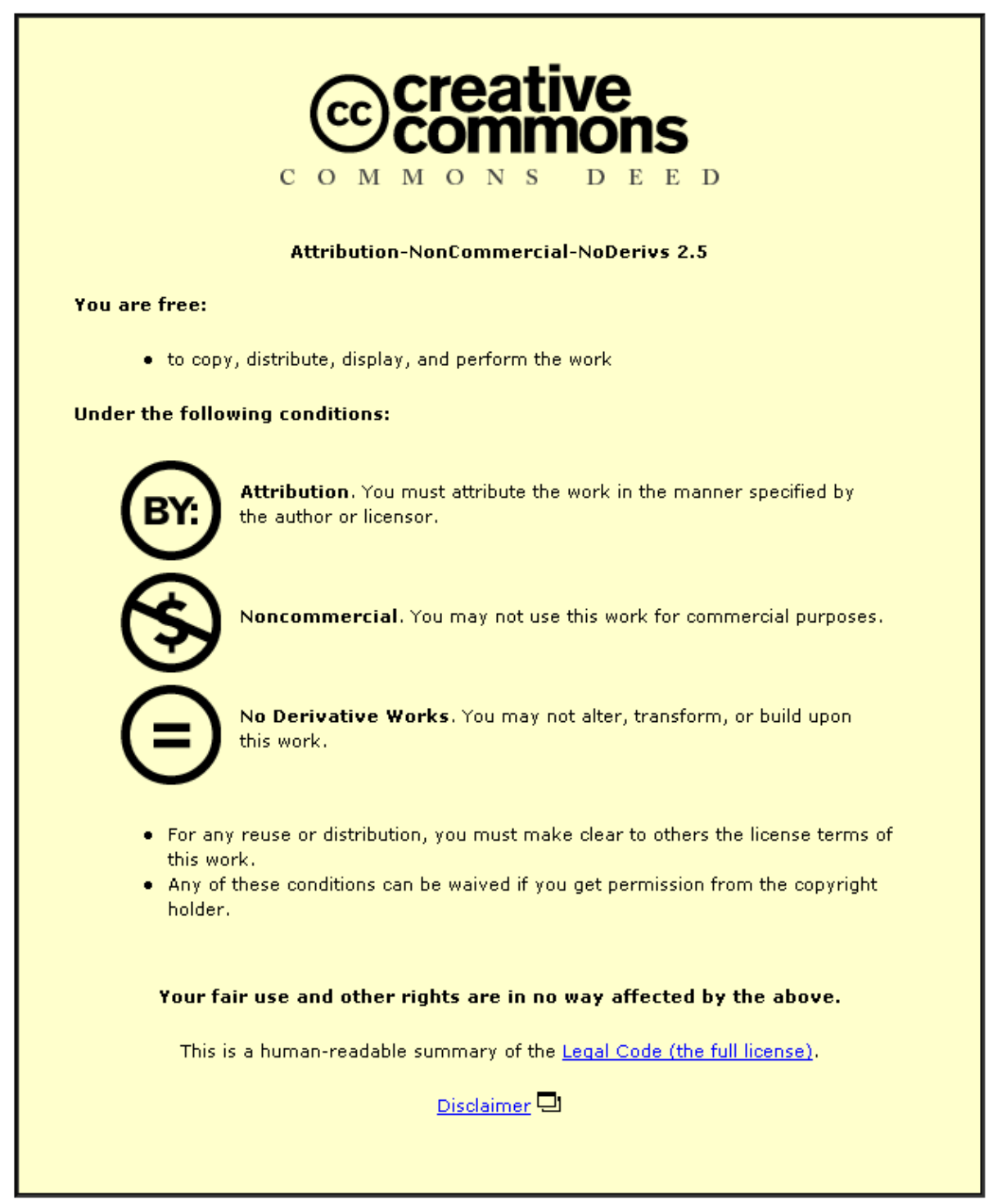

For the full text of this licence, please go to: http://creativecommons.org/licenses/by-nc-nd/2.5/ 


\title{
Rethinking Soft OR Interventions: Models as boundary objects
}

\author{
L. Alberto Franco \\ Scholl of Business and Economics, Loughborough University, Leicestershire, LE11 3TU, UK
}

\begin{abstract}
In this paper I draw on research on the role of objects in cross-disciplinary problem solving collaboration to make a case for the conceptualisation of models as potential boundary objects. Such conceptualisation highlights the possibility that the models used in Soft OR interventions perform three roles with specific effects: transfer to develop a shared language, translation to develop shared meanings, and transformation to develop common interests. If these roles are carried out effectively, models enable those involved to traverse the syntactic, semantic and pragmatic boundaries encountered when tackling a problem situation of mutual concern, and help create new knowledge that has consequences for action. I illustrate these roles and associated effects via two empirical case vignettes drawn from an ongoing action research programme studying the impact of Soft OR interventions. Building on the insights generated by the case vignettes, I develop an analytical framework that articulates the dynamics of knowledge creation within Soft OR interventions. The framework can shed new light on a core aspect of Soft OR practice, especially with regards to the impact of models on the possibilities for action they can afford to those involved. I conclude with a discussion of the prescriptive value of the framework for research into the evaluation of Soft OR interventions, and its implications for the conduct of Soft OR practice.
\end{abstract}

Keywords: Soft OR, models, intervention, boundary objects, knowledge creation, group decision and negotiation, problem structuring.

\section{Introduction}

The use of models has been an integral part of the emergence and establishment of operational research (OR) as a field. Pidd (2003, p.12) defines a model as: "an external and explicit representation of part of reality as seen by the people who wish to use that model to understand, to change, to manage and to control that part of reality”. There are many ways in which models are used in practice depending on the degree of human interaction involved in creating them and the intended frequency of use (Pidd, 2010). For example, models can be created to tackle a particular issue and discarded afterwards, as when developed and used by a group to make a one-off decision. Other models are built as part of formal decision support systems, as in the case of many spreadsheet-based models that have become embedded in organisational routines. Models give OR its distinctive identity, and help to distinguish it from other intervention approaches also concerned with tackling organisational problems such as, for example, organisational development (Burnes \& Cooke, 2012; Eden, 1978). And whilst it is recognised that the impact of OR work cannot be solely attributed to the use of models alone, it is evident that models perform a central and critical role in any OR intervention.

In this paper I examine the role of models in interventions designed to support the type of collaborative problem solving typically associated with Soft OR (Mingers, 2011). There is an extensive literature that offers accounts of the perceived or realised impact of different types of Soft OR interventions (e.g. Franco, Cushman, \& Rosenhead, 2004; Franco \& Lord, 2011; Mingers \& Rosenhead, 2004; Rouwette, Vennix, \& van Mullekom, 2002), as well as surveys of Soft OR adoption (e.g. Munro \& Mingers, 2002; O'Brien, 2011). Despite this evidence, however, a focus on what goes on inside the 'black box' of soft OR interventions has received little consideration in the literature to date (White, 2009). In particular, with notable 
exceptions (e.g. Ackermann \& Eden, 2011b; Franco \& Rouwette, 2011; Shaw, Ackermann, \& Eden, 2003), we know little about the complexities associated with core aspects of Soft OR interventions such as model-supported group processes. I argue that this focus is critical because it could help us answer a number of relevant questions related to the impact of models. For example, how do models enable or constrain interactions between those involved in a collaborative problem solving effort? How do models help to create new knowledge about the problem situation being addressed? What types of interactions take place when model outputs are invoked by group members and with what impact? And so forth. These questions are no doubt complex ones, but their answers can provide insight into the factors affecting model-supported group processes and outputs and, ultimately, intervention outcomes.

To conduct my examination, and in line with similar recent efforts by scholars working in the group model building tradition (e.g. Black \& Andersen, 2012; Zagonel, 2002), I draw on the body of organisation and social science literature that studies how different types of boundary objects help to overcome barriers in problem solving collaborations (e.g. Bechky, 2003a, b; Carlile, 2002, 2004; Henderson, 1991; Star, 1989; Star \& Griesemer, 1989). This literature is relevant to Soft OR because it provides a useful means to better understand the type of model-supported problem solving collaborations that are central to Soft OR practice (Franco, 2008), and also highlight the conditions under which models can become boundary objects during group interaction.

In what follows I explore the relationships between problem solving collaboration, knowledge creation, and boundary objects, and extend it to the context of Soft OR interventions. This is turn enables the conceptualisation of models as potential boundary objects, with specific roles and associated effects according to the type of boundary faced. These roles and effects are then illustrated via empirical case vignettes drawn from an ongoing action research programme that studies the impact of Soft OR interventions in a variety of organisational settings. Next, building on the insights generated by the case vignettes, I develop an analytical framework that articulates the dynamics of knowledge creation within Soft OR interventions. The framework can shed new light on a core aspect of Soft OR work, especially with regards to the impacts of models on the possibilities for action they can afford to those involved. I conclude with a discussion of the prescriptive value of the framework for research into the evaluation of Soft OR interventions, and its implications for the conduct of Soft OR practice.

\section{Theoretical background}

Much recent organisation and social science literature has accounted for the role of objects in cross-disciplinary collaboration using the notion of 'boundary objects' (Bechky, 2003b; Carlile, 2002, 2004; Carlile \& Rebentisch, 2003; Levina, 2005; Levina \& Vaast, 2005; Nicolini, Mengis, \& Swan, 2012; Star, 1989, 2010; Star \& Griesemer, 1989). This body of literature highlights the capacity of objects to support cross-disciplinary collaborations, including problem-solving collaborations such as those typical of Soft OR interventions (Franco, 2008). In the discussion that follows I will concentrate mainly on the work by Paul Carlile (2002, 2004), whose account is perhaps one of the fullest and most widely read in this literature.

\subsection{Problem solving collaboration, knowledge creation and boundary objects}

Carlile (2002, 2004) argues that problem-solving collaboration is typically associated with the need to create new knowledge within or across organisations. This need arises because 
novelty in the form of, typically, environmental changes requiring new organisational responses (e.g. a new product, service or process), is present. In such cases, a diverse group of experts, each one possessing domain specific knowledge and practice (e.g., about design, manufacturing, sales, safety, etc.), is typically formed to engage in a collaborative problemsolving effort. The specialization of group members' knowledge and practice creates boundaries associated with differences in the perspectives and type of knowledge group members have, and dependencies that hold important consequences for the particular tasks their respective functions perform. These boundaries are mostly evident in group members' interactions, making problem-solving collaboration, and thus new knowledge creation, a complex and challenging task.

There are three knowledge boundaries, namely, syntactic, semantic and pragmatic (Carlile, 2002, 2004), which present increasing levels of complexity and difficulty for creating new knowledge. In a syntactic boundary, difficulties are created by divergence in the symbols, labels and jargon used by group members due to their specialised knowledge, roles and organisational affiliations. The challenge for group members here is how to represent and communicate their knowledge to one another. Provided a common syntax or shared language is established and used by group members, then communication across the boundary is reasonably straightforward. However, when the differences in the amount and specialisation of group members' knowledge, and the dependencies on one another's knowledge to complete the problem-solving task, appear unclear or ambiguous a semantic boundary is then faced. These interpretive differences limit effective communication and knowledge sharing among group members, and thus shared meanings need to be developed in order to transfer knowledge across the boundary.

The process of developing shared meanings is likely to reveal consequences for group members' interests and incentives which, if adverse, will create potential for conflict. In this case we are faced with a pragmatic boundary. Where group members have different interests and incentives, knowledge developed in one area may have negative consequences for another and so be resisted. Under these circumstances, the shared interpretations developed for dealing with differences and dependencies at the semantic boundary will be insufficient to generate the level of collaboration required for problem solving. This is thus the most socially and politically complex type of boundary, as group members are required to negotiate meanings and be willing to transform knowledge and interests from their own specialised domains. The critical challenge here is changing knowledge that is 'at stake', and to create new knowledge as a result (Bechky, 2003a, b; Carlile, 2002, 2004).

There is an extensive literature that examines how different types of boundary objects help traverse syntactic, semantic and pragmatic boundaries within problem solving collaborations (e.g. Bechky, 2003a, b; Carlile, 2002, 2004; Carlile \& Rebentisch, 2003; Henderson, 1991; Nicolini et al., 2012; Star, 1989; Star \& Griesemer, 1989). A boundary object is a shareable and tangible artefact around which group members can interact about a problem situation of concern, and may include objects such as repositories and standardised forms (Star and Griesemer 1989); sketches and drawings (Henderson 1991); prototypes (Bechky 2003b, Carlile 2002, Pawlowski and Robey 2004); strategy tools (Jarzabkowski, Spee, \& Smets, 2013; Kaplan, 2011), and more abstract objects such as narratives (Boland and Tenkasi 1995). When working within and between organisations, individuals and groups orient towards boundary objects in terms of their affordances (Gibson, 1986; Hutchby, 2001), namely, the different possibilities they offer for action. For example, a prototype can make 
specialised knowledge tangible and offer opportunities for discussing design issues between representatives of different professional groups, departments, divisions or organisations. This 'tangibility' can be said to be the prototype's affordance.

According to Carlile (2002, 2004), to be useful within the context of a problem-solving collaboration, objects must afford group members with opportunities to: (1) represent and transfer their knowledge by providing them with a common syntax for communication ; (2) translate their knowledge by enabling the specification and learning of knowledge differences and dependencies; and (3) draw on, change or negotiate its context so that they can apply and transform what they know. In other words, a useful object is one that helps group members to deal effectively with the syntactic, semantic boundaries discussed above. When this happens an object is said to have become a boundary object (Barley, Leonardi, \& Bailey, 2012; Bechky, 2003b; Boland \& Tenkasi, 1995; Carlile, 2002, 2004; Levina \& Vaast, 2005; Pawlowski \& Robey, 2004; Star \& Griesemer, 1989). Consequently, not all objects are boundary objects per se. Provided they become one to those involved, changes in knowledge and practices across group member's functional or organisational constituencies are thus likely to follow (Bechky, 2003b; Carlile, 2002).

In the next section, and in line with similar recent attempts by scholars working in the group model building community (e.g. Black \& Andersen, 2012; Zagonel, 2002), I extend the notion of boundary objects to the case of models developed in Soft OR interventions. This conceptualisation can help us better understand the affordances that models can provide to those working across interaction boundaries and, at the same time, highlight useful criteria against which the effectiveness of Soft OR interventions may be assessed.

\subsection{Models as potential boundary objects}

The link between Soft OR and knowledge creation has been argued by some scholars such as Eden (1992) and, more recently, Keys (2007a, b). Indeed, whilst Soft OR interventions can have many purposes (see, for example, the discussion in Connell, 2001), knowledge creation is arguably a significant output of Soft OR interventions designed to tackle problem situations demanding novelty in their treatment. The need for novelty arises because existing approaches to address the situation may have proved insufficient in the past, or there is a belief by those concerned that their use may perhaps exacerbate the situation. To make progress, then, a group of individuals with domain-specific understandings of and interests in the situation is typically gathered to participate in a model-supported problem-solving collaboration, with a view to developing new knowledge about, and novel responses to, that situation. New knowledge arises when the meanings attributed to the problem situation change, as modelling helps to transform the context and relationships between the different elements of that situation (Ackermann \& Eden, 2010; Eden, 1992).

Model-supported problem-solving collaborations that are typical of Soft OR interventions (see, for example, Franco, 2008) also require that syntactic, semantic and pragmatic boundaries be traversed, and models have in this process similar supporting roles to those discussed above. To traverse a syntactic boundary, models perform a transfer or communication role that helps group members to develop a shared language that enables them to specify and share their perspectives and knowledge differences and dependencies related to the problem situation. The variety of classification structures and coding procedures embedded within models are intended to create this shared language. For example, Strategic Choice models (Friend \& Hickling, 2005) structure group members' discussions in terms of 'decision areas', 'uncertainty areas', and 'comparison areas'. 
Similarly, SODA models (Ackermann \& Eden, 2010) require group members' inputs to the discussion to be codified using bipolar nodes organised as hierarchies of argumentation. When different types of models need to be used to communicate at the syntactic boundary, specific procedures are developed to help group members move between different models (see, for example, Howick, Ackermann, \& Andersen, 2006). Having a shared language through the use of models, however, does not necessarily mean that group members will understand models in exactly the same ways. At the syntactic boundary, models only enable group members to have different types of conversations (Franco, 2006) without enforcing commonly shared meanings (Boland \& Tenkasi, 1995).

A model acting only as a communication tool will not be sufficient to traverse a semantic boundary. To traverse this boundary models also must function as translation devices. In this role models help group members to create sufficient shared meanings to accommodate and learn about interpretative and knowledge differences and dependencies. The models created within Soft OR interventions represent these differences and dependencies in terms of relationships between concepts, activities or stakeholders, relations of similarity or influence, and relationships between options. It is the visual and accessible nature of these representations, together with the interactive analyses they can facilitate, that are claimed to be of particular value in increasing group members' understandings of their differences and dependencies, and thus help them learn (Franco \& Montibeller, 2010).

Finally, models also have a role to play with regard to pragmatic boundaries, which are commonly experienced in most Soft OR interventions. Pragmatic boundaries arise when particular shared meanings emerging during interaction make group members' knowledge and interests more salient and at stake, which generates conflict that needs to be managed through negotiation. Typically, it is the group members' anticipations of the consequences, perceived or real, of particular shared meanings that generates this conflict (Ackermann \& Eden, 2011b). The pragmatic boundary can be traversed when the model performs a transformative role that enables group members to manage an open negotiation that develops common interests, and creates new knowledge with change implications about the problem situation being addressed. Models can help to manage the negotiation by allowing group members' to consider their needs, choose what to include or exclude from the discussion, and reflect any changes in knowledge, interests or relations that may emerge incrementally during interaction. This transformative role has also been referred to as 'transitional', 'facilitative' or 'negotiative' by other scholars (e.g. Eden, 1992; Eden \& Ackermann, 2001; 2004; Franco \& Montibeller, 2010).

Table 1 below summarises the preceding discussion. In the first column each type of boundary is categorized according to the complexity of the boundary faced by those involved in a Soft OR intervention. The second and third columns highlight the different roles models perform at each boundary (transfer, translation, transformation) and their associated effects (shared language, shared meanings, common interests), respectively. It is important to stress that as we successfully traverse each boundary, the roles and effects of models in more complex boundaries encompass those associated with less complex boundaries. For example, when faced with a semantic boundary, models must be able to operate as both communication and translation tools. Similarly, when a pragmatic boundary is faced, those involved must be able to use models as communication, translation, and transformation tools. Not surprisingly, models developed in most Soft OR interventions are required to perform all three roles. 
PLACE TABLE 1 ABOUT HERE

Building on the theory of boundary objects discussed above, I posit that the extent to which syntactic, semantic and pragmatic boundaries are traversed in Soft OR interventions will depend upon whether the models created can become boundary objects 'in-use' (Levina \& Vaast, 2005) to those involved. This would require that models perform the three roles specified in Table 1 successfully, and thus help in creating a shared language, shared meanings and common interests during group members' model-supported interactions. However, it is possible that models do not achieve these effects in some cases. For example, as Ackermann and Eden (2011a) note, this can happen when models, and the analyses they enable, are used either symbolically to deflect attention away from discussing the real issues, or as a vehicle for imposing particular perspectives, in which case new knowledge and change is unlikely to be achieved. In these cases, models are not (or will not become) boundary objects in-use. Therefore, their actual potential to become boundary objects deserves closer empirical examination, which I undertake in the next and the later sections.

\section{Methodology}

In this section I will use illustrations drawn from an ongoing action research programme into the impact of Soft OR interventions in a variety of organisational settings including both, intra- and inter-organisational work in the private, public and non-for profit sectors. The research involves collecting and analysing intervention data produced since 1998, and comprises detailed assessments of the perceived and realised outcomes of interventions in which 'facilitated modelling' workshops (Franco \& Montibeller, 2010) are a key element. For the majority of these workshops I acted as a facilitator-modeller, either in a leading or coleading capacity, and in a few cases I performed a non-participant observer role. These workshops constitute the main unit of analysis on this action research programme, and data collected through semi-structured (and post intervention) interviews is supplemented with data obtained from intervention documents (e.g. inputs, outputs, process notes, reflections) and, when possible, workshop audio and video recordings. The accumulated data is coded using software such as Atlas.ti (www.atlasti.com) and Decision Explorer (www.banxia.com), and analysed following the principles of inductive theory building (Dougherty, 2002; Eisenhardt, 1989; Strauss \& Corbin, 1998). Part of this research has already appeared in the OR literature (e.g. Franco, 2007, 2008; 2009).

Although the action research programme had not initially focused on the notion of models as potential boundary objects, their importance emerged inductively from the process of analysing the data. Specifically, attention to the role of models across boundaries was the result of noting that not all interventions led to (intra or inter) organisational change. Consequently, by focusing on each data source (interviews, intervention documents, notes, reflections, and audio or video recordings where available) and looking for similarities and differences across data sources, I generated tentative explanations that could account for the intervention outcomes observed. I then compared and discussed these initial explanations with colleagues who had also participated in the interventions (e.g. as co-facilitators, comodellers, observers), as well as with other academic practitioners who had similar experiences of intervention impacts. I then moved back and forth between data and theories on boundary objects, interrogating the empirical materials to assess whether my initial explanations were supported by the data and, conversely, whether the theory helped to make sense of the empirical data (Yanow \& Schwarz-Shea, 2006). The empirical material analysed 
below does not, however, represent a comprehensive assessment of the effectiveness of Soft OR interventions. Rather, the aim of the discussion below is to illustrate the usefulness of a particular theoretical conceptualisation using case vignettes as empirical illustrations.

The selected case vignettes are of particular value because they provide a good illustration of the role of models across the type of boundaries I am concerned with (Eisenhardt \& Graebner, 2007). Whilst working across boundaries is common place within single organisations (e.g. Carlile, 2002), I selected two vignettes from interventions conducted in multi-organisational settings because boundaries in this type of setting are particularly salient. In addition, each vignette illustrates contrasting intervention outcomes (significant change in one case; little change in the other case), which is needed in order to assess the potential usefulness of the notion of models as potential boundary objects. Detailed accounts of the interventions from which the case vignettes are drawn have already been published (Franco et al., 2004; Franco \& Lord, 2011), and thus these accounts will be reappraised here in the light of the conceptualisation of models as potential boundary objects. As already stated, it should be clear that the purpose of the empirical vignettes is not to test this particular conceptualisation but, rather, to illustrate its value in increasing our understanding of the extent to which models can help to traverse syntactic, semantic and pragmatic boundaries. In what follows I will first briefly describe the intervention context, and then how models were developed and used by those involved. Finally, in the next section, I will relate these aspects to the boundary concepts discussed earlier and summarised in Table 1, drawing on selected excerpts from intervention data.

\subsection{Case vignette 1: Developing a project review process for a construction partnership}

The move towards partnering in the UK construction industry in the mid-1990s led many sector firms to engage in collaborative ventures. During that time, Whitbread plc were in the early stages of a partnering arrangement with their service providers, which involved a series of hotel refurbishments to meet the standards of their recently acquired Marriott franchise and the construction of new Marriott hotels. Whitbread were looking for ways to add value to their franchise projects, and their participation at that time in an industryacademic research collaboration provided an opportunity to achieve this objective (for details, see Franco et al., 2004).

Given the wide range of specialist organisations participating in a construction project (e.g. contractors, designers, quantity surveyors), considerable emphasis was placed by Whitbread on developing appropriate systems and procedures for project management and review. The research team was thus tasked to develop a project review process to make learning within Whitbread's partnership project teams, and across all partner organisations, more effective. What made this task particularly challenging was that it was dependent on the effective collaboration between Whitbread and their partners, who were used to operate in a sector with a long tradition of adversarial relationships between firms, and thus posed significant barriers to communication, knowledge sharing, and learning.

Members of partnership project teams were often in direct contact with one another through regular meetings, which provided the main mechanism for cross-disciplinary discussions and decision-making. At meetings, detailed progress reports were presented which allowed project progress to be assessed against established milestones and deliverables. Drawing on Whitbread's previous experience, an initial project review process based on value management techniques (Connaughton \& Green, 1996) was tested through a couple of workshops. These techniques, however, could not adequately represent the differences and 
dependencies that were apparent during project team members' discussions. The identification of these aspects was deemed necessary in order to generate practical crossorganisational lessons for future projects (see Franco et al., 2004).

After this initial experience, the research team developed a project review process intended for use by all construction project teams within the Whitbread partnership. The new process was captured in a simple diagram (a process model), with review workshops as a key element (see Fig 1 in Franco et al, 2004: p.591). The format of these review workshops was designed around a soft OR methodology, namely, the Strategic Choice Approach (SCA) with its problem solving stages (i.e. shaping, designing, comparing, choosing), modelling techniques (e.g. analysis of interconnected decision areas), and tools (e.g. decision graphs, comparison tables, commitment packages) (Friend \& Hickling, 2005). The new review process was tested in three partnership projects and significant time was spent in developing scripts for how to run the project review workshops, creating a common language, training a Whitbread facilitator (who was also a member of the research team), and making changes to the process that reflected concerns.

One of the initial challenges for the partner organisations was to operate within an 'open book' format, which meant giving up some of the control over information (e.g. cost) each organisation was used to having. A subsequent challenge was getting the partners to conduct project reviews using a particular structured format, and recognise their benefits, despite concerns about whether the reviews and their proposed format would only help to legitimise the intentions of the more powerful players (e.g. Whitbread's).

After months of developing and fine tuning, the final review process was rolled out across the partnership. The effectiveness of the new process and associated tools was significant, particularly with regards to reducing the time devoted to the settlement of project accounts, which had an impact on cost reduction. Over the next few years the new project review process became part of Whitbread's project management handbook, which every project manager had to follow. Whitbread also extended the use of the new review process from their Marriott franchise projects to a much larger programme of Travel Inn renovations (for more details, see Franco et al., 2004).

\subsection{Case vignette 2: Developing a strategic budget for a teenage pregnancy strategy group}

In 1997, the New Labour government in the UK coined the term 'joined-up government' to capture its approach to public sector reform. The term encompassed a wide range of activities and developments intended to improve services for particular social groups or populations, including substantial cross-organisational work to tackle complex social and economic issues. One such issue concerns the impact on welfare systems and society as a whole caused by people becoming disconnected from schooling and further education, and hence the labour market. Drug-taking, crime, family breakdown and teenage pregnancy are often cited as possible explanations for this phenomenon. With regards to the latter, teenage pregnancy rates in the UK were in the early 2000s similar to those in the 1970s, whereas they had halved in most Western European countries. Tackling teenage pregnancy was thus a priority for the government and, in 2002, all local authorities in England were required to set up a Teenage Pregnancy Strategy Group (for more details of the background see report by the Social Exclusion Unit 1999).

The client of the intervention described below was one such group working for an English borough that encompasses a large area in East London that has significant issues of social 
deprivation and poverty, mixed faiths and multi-ethnicity. In addition, the area has a disproportionately young and needy population and a much higher rate of pregnancy amongst teenagers than in other boroughs of the city. Indeed, the borough has one of the highest teenage pregnancy rates in the country. In 2003, the number of conceptions for teenagers within the 15 to 17 year-old range was about 55 per thousand, and the borough was under high pressure to bring this number down to below 30 per thousand by 2010. The team tasked with making the strategic decisions to achieve this target, hereafter referred to as the Teenage Pregnancy Strategy Committee (TPSC), was made up of representatives from the borough's council, the National Health Service, the education authorities, and other stakeholders such as the voluntary sector which included young parents' representatives. Its budget was made up of a complex mix of direct funding, contributions from the participant organisations, and government incentives for achieving certain targets and key performance indicators. The TPSC wished to explore more effective and efficient ways to achieve their teenage pregnancy rate targets, and agreed to focus on the budget prioritisation process as a useful mechanism to achieve this (for details, see Franco \& Lord, 2011).

The design of the intervention followed a mixed-method approach (Howick \& Ackermann, 2011) comprising two phases: (1) a problem structuring phase using SODA techniques (Ackermann \& Eden, 2010; Eden, 1988, 2004) to achieve a shared and improved understanding of the issues related to teenage pregnancy among key stakeholders; and, (2) a budget evaluation phase using portfolio decision analysis techniques (Salo, Keisler, \& Morton, 2011) to highlight a portfolio of projects which would produce the highest value in relation to the aims of the TPSC. The main output of the problem structuring phase was a group causal map developed interactively in a one-day workshop, which brought to light the different perspectives of those involved. The map helped to identify a range of potential projects and suitable evaluation criteria that informed the subsequent budget evaluation phase. Here, a portfolio model was populated and used by key stakeholders in a decision conference workshop format (Phillips, 2007; Phillips \& Bana e Costa, 2007).

The portfolio model challenged the claimed impact of projects that were considered by some stakeholders as core to the TPSC strategy. In particular, the model results suggested that some of the projects within the area of clinical services were not as efficient in terms of their benefit-cost ratios as previously thought. The implications of adopting alternative and more efficient project portfolios were intensely discussed, and the model was adjusted to reflect the discussions. In a subsequent budget planning meeting of the TPSC, and counter to what the model results had indicated at the workshop, it was agreed that the projects within the clinical services area were still going to be funded, albeit from a mix of sources within and outside the TPSC. It was noted, however, that the actual impact of these projects would be closely monitored and the decision to fund them revisited in the following annual budget cycle.

The original accounts of the interventions on which the two case vignettes are based offer specific explanations for the effects and impacts observed. With regards to the intervention described in case vignette 1, Franco et al (2004) argued that the partnership relationship between Whitbread and their service providers was a major factor in the success of the project review workshops and, by implication, the designed project review process as a whole. Because a partnership, by definition, suggests a basic compatibility of purpose between those involved, Franco et al (2004) hypothesised that this background offered "a setting of multiple stakeholders within a context of broad agreement which needs to be made operational (p.598)”, which made it an appropriate setting for the implementation of Soft OR processes, methods, and tools. On the other hand, for the intervention outlined in case 
vignette 2, Franco and Lord (2011) argued that the salience of political considerations associated with the budgetary process, together with the multi-organisational nature of the TPSC, posed a serious challenge to the implementation of the model's recommendations. Although these explanations are plausible, below I will reappraise both accounts by adopting the lens provided by the conceptualisation of models as potential boundary objects discussed earlier. It is not my intention to provide an alternative or competing explanation to those provided in Franco et al (2004) and Franco and Lord (2011) but, rather, to complement their analyses with an exploration of the effectiveness of models and tools in traversing boundaries and creating new knowledge that has action implications. In this way my aim is to contribute towards a more robust understanding of the role of models as potential boundary objects in Soft OR interventions.

\section{Analysis of the case vignettes}

What follows is an analysis of the vignettes to illustrate the varied roles played by the models created in both interventions. It is worth noting that the models discussed here were not the only artefacts with potential to become boundary objects within the interventions. Indeed, artefacts such as workshop 'scripts' (e.g Ackermann, Andersen, Eden, \& Richardson, 2011), 'progress packages' (Friend \& Hickling, 2005), and process charts can also become boundary objects during an intervention. However, whilst these artefacts can also account for an intervention's impact, I contend that the active and critical role that models perform within Soft OR interventions in general, and Soft OR workshops in particular, needs to be highlighted, unpacked and better understood. With this in mind I will draw below on selected excerpts from intervention data as they relate to each type of boundary.

\subsection{Traversing syntactic boundaries}

Numerous syntax mechanisms were established to enable communication between participants within the workshops. In the case of vignette 1 , a base common language was established to enable partnership teams share their perspectives and knowledge about projects within project review workshops. Achieving this shared language was not straight forward but the result of several iterations to meet the specific needs of Whitbread and their partners.

"I think if you just did it without any refining you are talking a different language to what the
construction industry understand...I mean, if you've got academics writing it the one thing you
have to do is you have to get some industry input because no disrespect to academics but they
write things in a different language, as I found out."

(Hotel manager, case vignette 1)

Thus the need to keep the terminology used to build models understandable to workshop participants led to a re-examination and refinement of the language used. Terms such as 'project victories and successes', 'barriers to action', and so forth, were adopted to help specify the differences in perspectives and knowledge; whilst others such as 'interconnectivity' and 'cross-impacts' were retained to help highlight dependencies.

Similarly, for case vignette 2, a shared language was established to communicate about teenage pregnancy issues (causal mapping workshop) and the value of different projects intended to alleviate these issues (decision conferencing workshop). It was the procedures and taxonomies used to code and organise participants' contributions that helped TPSC members to communicate at the syntactic boundary. Such procedures (e.g. rules for entering and linking statements into the causal map; decision language that distinguished options, criteria, and criteria weights in the portfolio model; scoring and criteria weighting 
procedures) represented new ways of communicating between stakeholders, as noted by the following interviewee.

\begin{abstract}
"I certainly haven't had those conversations with the department before....it's not often that we sit down and really look in a very, very structured way as we did then, you know with all those different partners.”
\end{abstract}

(Prevention Sub Group Project Manager, case vignette 2)

Evidence suggests that the structured procedures helped participants to access and better appreciate others' perspectives, knowledge and experiences, which helped to reduce past communication barriers.

\begin{abstract}
"We've had people been invited to sit on the strategy board based on what jobs they do and not necessarily taking into account what job they do, where they've come from and what their values are. I found it useful and also it made me think of how I would approach my work with those particular people and understand some of the blocks I have had in my work with certain people.”
\end{abstract}

(Children's Rights and Sex Education Representative, case vignette 2)

In addition, participants were able to adopt the shared language and adapt the workshop procedures in routine cross-organisational interactions outside the remit of the intervention, enabling information and knowledge to be transferred within teams and across constituencies.

“....following my experience of the [workshop], what I learned from there, and how [the facilitator] run that and how you guys sort of backed that up...and I used that to do my own version of it. The headings really were the ones that you see on that document [pointing at document containing outline of review workshop process]...”

(Property Development Manager, case vignette 1)

\title{
4.2. Traversing semantic boundaries
}

The preceding discussion and case evidence suggests that a shared language and structured procedures helped participants in both case vignettes to communicate effectively at the syntactic boundary. It is unusual, however, for Soft OR interventions to be designed and deployed to support work only at this boundary. In the majority of interventions, differences in group members' understandings and interpretations of the problem situation may pose barriers to knowledge creation with action consequences, in which case models need to allow those involved to interpret and learn from each other's perspectives. In both case vignettes, the models developed in the workshops represented the central means through which the group discussions were organised. Specifically, group discussions were structured around model displays that tracked the ebb and flow of interaction. For example, in the following excerpt from one of the project review workshops (case vignette 1), the facilitation team is presenting the results of an initial attempt at structuring issues as 'decision areas' in a 'decision graph'(see Figure 1), which leads to a discussion aimed at interpreting the meaning of a project's 'brief'.

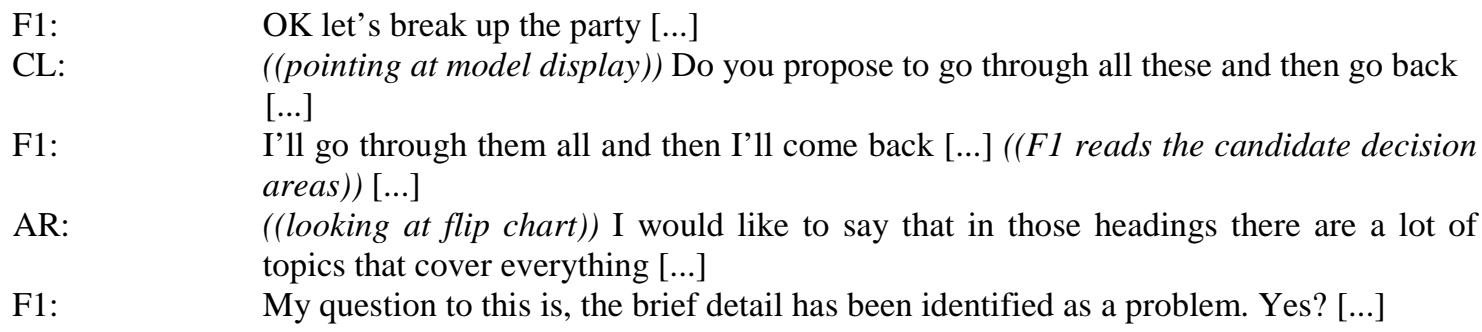




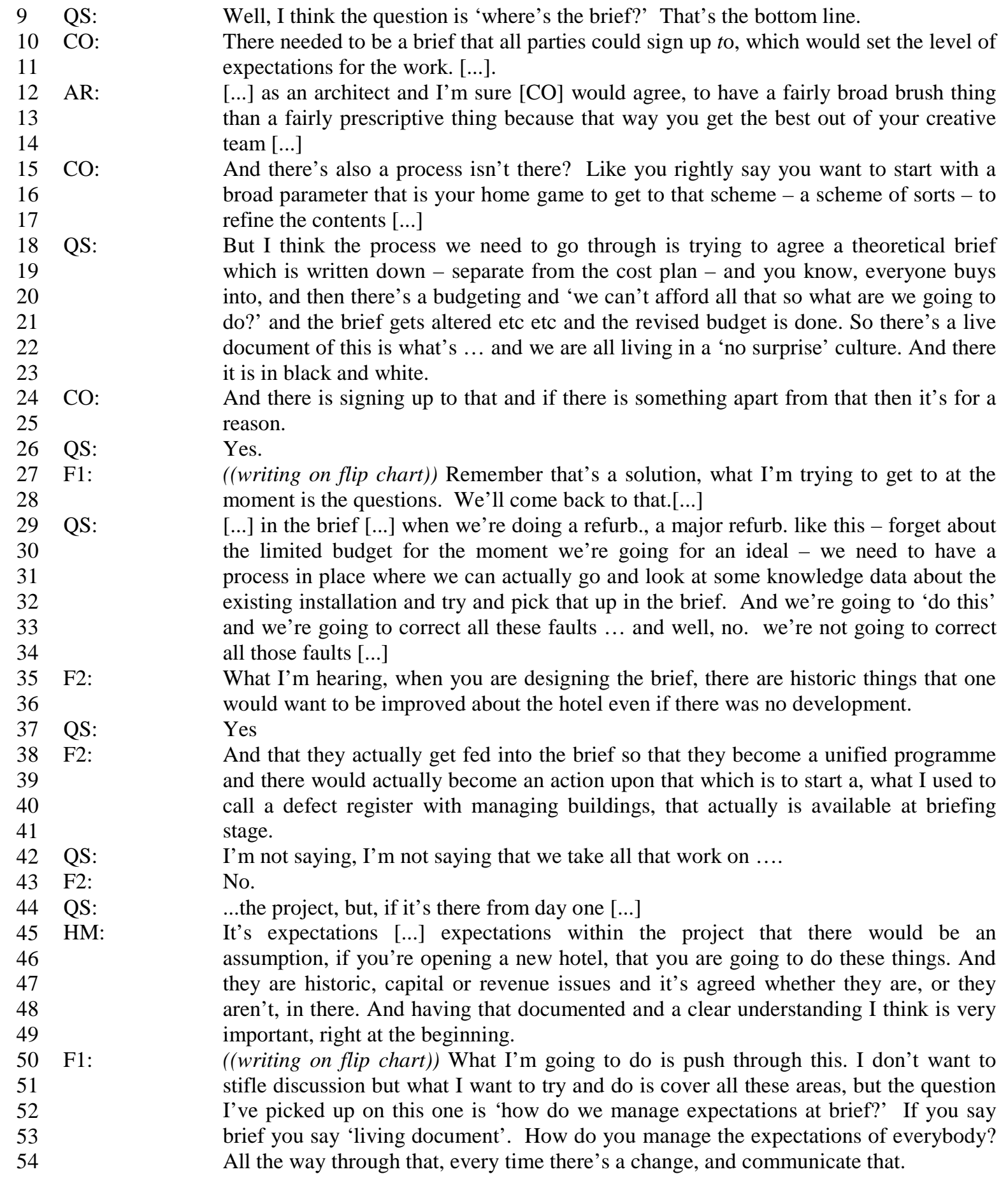

Key: $\mathrm{AR}=$ architect; $\mathrm{CL}=$ client representative; $\mathrm{CO}=$ contractor; $\mathrm{F} 1$ = facilitator 1 ; F2 = facilitator 2; $\mathrm{HO}=$ hotel general manager; QS = quantity surveyor. NB: The use of an ellipsis in brackets (i.e., [...]) following a statement indicates that interventions by one or more participants have been edited out.

\section{PLACE FIGURE 1 ABOUT HERE}

The segment above shows how group members, prompted by the presentation of the initial model, started offering their different understandings of the notion of a 'project brief'. Multiple meanings are evident in the segment, including brief as a 'detailed versus a generic 
document' (lines 12-13, 15-16, 31-32, 35-42), 'a fixed versus a living document' (lines 1617, 18-19, 21-22), and a means to ensure a "no surprises culture" (lines 22-23, 32-34, 44). At different times during the discussion, group members were gazing and pointing at the model display (lines 2 and 6; during other parts of the workshop some members even approached the display and then went back to their seats). In parallel, the facilitator was manually updating (lines 27 and 50) the model to track the evolving discussion, which involved entering, discarding, or leave pending for further consideration, the multiple meanings attributed to the project brief. By orienting towards a tangible artefact that captured their discussions, and making changes (through the facilitator) to that artefact to reflect the evolving discussion, group members were able to work together and to reconcile different meanings given to different aspects of the brief. The model facilitated the multiple translations necessary for the development of shared meanings among group members, which in the case of the segment above led to the adoption of 'managing expectations related to the brief' (lines 10-12, 24-26, 45-54) as a decision area.

The models developed in both case vignettes (decision graphs, maps, portfolio models) helped group members organise their collaborative problem solving discussions, by acting as concrete visual objects around which they learned about each others' perspectives and the consequences of different proposals for action.

"I think at least when the issues came out and they were up on the flipchart at least everybody concentrated on that particular issue....It kept it focused and kept people in unison.”

(Design Subcontractor, case vignette 1)

“...it's just that thing about putting all your ideas up and then something links it all up together somehow....I thought that was useful because obviously there were so many different ideas and people are coming from different places with different agendas. I thought it was quite useful that they were all up there at some point.”

[Children's Rights and Sex Education Representative, case vignette 2)

"I think it was good to see the visual representation, maybe some people use their visual perception much more...Yes, I think so, I quite liked seeing it in front of me on screen and then seeing how what effect the changes [to the budget] had....so we could start to see what the shape of the [efficient frontier] curves were and where things were on the graph and I thought I liked that representation.”

(Co-Chair of Teenage Pregnancy Strategy Group, case vignette 2)

Furthermore, models not only translated between the various ways of knowing of group members, but also acted as a mnemonic and traceable device for the shared understanding being developed during discussions around the models.

“Coming with a list of items that everybody has put up together in effect, let's run through that and select as a group it's a good way of doing it. It also gives the opportunity, by running through the list, things will stick in your head.”

(Partner Contractor, case vignette 1)

"I was quite interested in how the data was gathered and quickly transposed and that was good because you could see the data working as you processed it and I like that element.”

(Learning and Schools Representative, case vignette 2)

It was the incremental transformation of the models into concrete artefacts (e.g. decision graphs, maps, portfolio models) that changed both the characteristics of the group interaction and what was learned across different professional specialisations represented in the groups. Group interactions at the semantic boundary were also shaped by the analyses enabled by the 
models. This was particularly salient in case vignette 2, in which models were developed using computer support that allowed interactive analyses 'on-the-spot' (for details, see Franco and Lord 2011).

"I liked how you sort of cut and pasted and drew bands around the data. I liked that process, that quick turnaround of data to show some tangible evidence and the links and connections, I liked that process.”

(Learning and Schools Representative, case vignette 2)

"I think [the model] helped...to make sense and put things in to order and we could see what the consequences of our decisions were and then make some changes or give it a different weight or balance. You could see the different options quite quickly couldn't you and choose between them in a way you couldn't do without it"

(Co-Chair of Teenage Pregnancy Strategy Group, case vignette 2)

"Yes, we rated all those and then at the end of the amount of all rating certain sections you where then able to highlight what had come out as our best value for money, you know it wasn't compared to the impacts and we couldn't, that's something that you can't actually assume in your head really you can't see all those areas in your head, so it was useful for that"

(Prevention Sub-Group Project Manager, case vignette 2)

Finally, interaction with models led group members in both case vignettes to learn about their critical dependencies, particularly in terms of the influence their work had on each others' specialised areas of activity.

"We are more...much keener in getting a link directly into the client or multi-directly into the client to establish the information we are asking for, that the information we are getting is correct, that it has been ok'd by everybody that needs to have an input into it. And the way you were just putting it there was a nice way, a subtle way of saying that there are some things in which the client needs to get its act together!

(Partner Contractor, case vignette 1)

"[It] allows you to find out more about what the people are doing, and to understand better other parts of the process will always inform what you're doing, and even if it's to change what you are doing it gives you a better understanding of how you may... but it does probably change the path that you're on because it makes you realise who you need to interact with and where the gaps are and clearly communication and making sure nothing falls through the system.....So I think yes finding out what are the people are doing, how they do it, where they do it, how we can interact with them, that's always got to be a good thing."

(Family Planning Lead, case vignette 2)

"I think it made me think about different perspectives on the work, so obviously we were looking at it from the point of view from the teenage pregnancy strategy which I work within to a certain extent but that has lots of different branches. For example thinking about getting young people back into education, employment and training, it's not something that my project really focused on although that is an aim that's of lesser importance of some of our other broader aims, so it made me think about what bits of work actually impacted in that area, so I could see that some of the things we were doing also had a role to play in terms of getting young people back into education, employment and training, so that perhaps shifted them up slightly in my perception of their value of work.

(Prevention Sub-Group Project Manager, case vignette 2)

To summarise, the case evidence suggests that models developed played a critical role in the specification of, and learning about, (factual or perceived) differences in group members' perspectives and dependencies, and in the development of shared meanings about what was of consequence. Overall, across the two case vignettes, differences in understandings and 
interpretations were largely overcome with recourse to the different opportunities for action afforded to workshop participants by the models developed.

\title{
4.3. Traversing pragmatic boundaries
}

For case vignette 1, a clear pragmatic boundary existed due to the different interests that needed to be reconciled between Whitbread and their partners. Specifically, there was a disparity in the aspirations and expectations related to partnership work, as illustrated in the contrasting views offered by a hotel manager and a partner contractor in the excerpts below.

“...we accept that we probably got in terms of [name of partner contractor], we probably got the best the industry can offer. But is it good enough? And I don't think it is. I don't think it is. If we are going to go into partnering big time and in the future, then what we have to do is we have to say to these guys "look as a partner you are going to have to start to live some of the same values that we do....we are going to have to involve you in our spirit to serve, our culture of training, and you know we maybe even charge you for doing it but you will benefit...so that you think, you know, you have a similar mindset to us...but you don't...you know you are not stuck in this paradigm paralysis as I call it”.

(Hotel General Manager, case vignette 1)

\begin{abstract}
"Yes we do [have a communication problem on partnering] because bear in mind that in the early days of partnering and people are having - people who shall remain nameless - were organising partnering forums and seminars etc. And these three rings kept being flashed up all the time and the message saying ' you are expected to exceed expectations because if you don't, other partners will'. So, in reality, that's what happened. So I don't think anybody felt that being a partner made them totally secure"
\end{abstract}

(Partner Contractor, case vignette 1)

During the project review workshops, models were used to explore the consequences of differences and dependencies between Whitbread and their partners, which revealed adverse consequences due to competing interests, creating pressures to develop alternative ways of defining what the problem was and what solutions were deemed acceptable to all. For example, in one project review workshop, examination of the model (decision graph) led to the discovery of 'snagging' (i.e. the process of identifying defects in the final construction product) as a critical decision area needing urgent attention. The discussion about snagging surfaced group members' knowledge and different understandings, as well as interests that were at stake due to cost settlement issues and expectations of future partnership work. Within this context, it was the opportunity to shape the agenda and change direction during the workshop to cater for the local needs of group members that was deemed significant in the negotiation and implementation of the agreements that followed (see Franco et al 2004).

"I did appreciate that obviously you did change the direction it was going at [workshop location] to cater for the issues that we had, like the snagging issues, because they were at the top of the agenda at the moment”

(Property Development Manager, case vignette 1)

The opportunities to choose what to include or exclude from workshop discussions were realised by group members' ability to draw upon, alter, and manipulate the contents of the models developed. Furthermore, the case evidence suggests that during the workshops group members exhibited an attitude that reflected the kind of (partnership) relationship they wanted to have and sustain, providing an appropriate medium within which new knowledge was created and joint agreements were reached. 
"It was good in as much as the team were very much of one mind in terms of the things that went right and went wrong. And [they] were constructive about the things that had gone wrong and were keen to learn ways to improve those."

(Design Subcontractor, case vignette 1)

"In terms of the results that we had [at the workshop] I feel that they were sounder because they were discussed by all parties and all parties signed up to them and jointly signed up to them as well."

(Partner Consultant, case vignette 1)

"What happens...someone said 'Oh I have an issue with directs', for example, and someone says 'Oh yeah, they were...' and this sets other people to say “well he’s right or he's wrong”

(Partner Consultant, case vignette 1)

"I think we moved on even from then to now in the relationship with the partner subcontractors and in the understanding of the quality of the service that people aspire to. It takes quite a long time to move from competitive tendering to a long-term relationship where people want to work together....I think (the workshops) lent substance and credibility to the whole thing....So I think (the workshops) do a lot to support the right objectives for the people who are committed to this direction.”

(Property Development Manager, case vignette 1)

By contrast, the models developed in case vignette 2 (causal maps, portfolio models) were deemed less effective in facilitating group members' interactions at the pragmatic boundary. In case vignette 2, a pragmatic boundary existed due to tensions in relation to how different professional groups approached the issue of reducing teenage pregnancies. This tension was particularly noticeable between clinically-driven solutions to reducing teenage pregnancies on the one hand, and those concerned with children's rights and religion issues.

“There's some things you know, like for me I sit on a board and you think OK this s all about reducing teenage pregnancy and you think up some ideas where people are coming from and then stuff comes up on that board and you think shit, where did that come from? I remember actually a couple of things that came up, I was thinking 'oh my god, what are they doing these people?'... I mean it’s fairly basic stuff about making assumptions about people but also ultimately we see some clinical GPs out there in the general population and they are not all going to think as liberally as I do...”

[Children's Rights and Sex Education Representative, case vignette 2)

"I mean on the day at [workshop location] there was the chap who was a [religion] counsellor or something but he's someone who isn't part of the decision-making group, he wasn't someone we knew very well, and I think there was some anxiety about having him going to that day because we kind of felt careful about what we said, and we knew that his support generally makes quite a lot of difference to how things will run through the council...I think he would have always had some anxieties about clinical services.”

(Family Planning Lead, case vignette 2)

Indeed, these tensions became salient at the group mapping workshop, when the value of clinical services against other services was discussed. However, the conflict that surfaced at that workshop was not fully resolved.

"I remember we started a discussion around sex education and religion and things like that. We were going to get in a debate about... there was some stuff around emergency contraception and religion and then terminations. I thought that would be really interesting but we never really picked that up.”

[Children’s Rights and Sex Education Representative, case vignette 2)

"Maybe that's where people would come in from their specialty interests. Maybe [name of Family Planning Lead] was voting for prevention, [name of Learning and Schools 
Representative] was voting for the educative. It was evident that we were short of time but it did lead to quite a bit of conflict I remember on the day, quite a heated discussion between the two issues and it wasn't really resolved."

(Co-Chair of Teenage Pregnancy Strategy Group, case vignette 2)

Furthermore, the portfolio model developed in the decision conference workshop did not play the transformative role that would have enabled group members to create new knowledge with change implications. Instead, rather than being the subject of an open negotiation, advocates of clinical services repeatedly highlighted the importance and value of these services, presenting them as non-negotiable and fixed, despite the portfolio model results indicating their low benefit/cost ratio scores relative to other services.

"I suppose I think we were all quite..., when you did that presentation I think we were all quite
shocked, I mean me because you know the clinical services are something that I have a direct
relationship with but I think lots of other people were quite shocked because when we went to
the initial meeting in [workshop location] I think even then we were being surprised by what
was coming out, you know when we did the map because the themes had been much more of
an emphasis on some of the work with religious groups for instance and I think we'd always
thought of the clinical work, the clinics of being core if you like, fundamental as part of what
we did and it wasn't just me but other people who didn't have such a direct link with them....if
it comes down to having to make staff redundant then it always makes you think...because it
was very clear that some of the [clinical services] were perhaps not going to be prioritised on
your [portfolio] model it made me think more clearly what would happen if you didn't have
those [name of service] and there's so much else that kind of flows into the [name of clinical
service] and if it comes down to actually stopping young people getting pregnant you don't
have the clinical services to provide contraception then how are we going to stop young
people getting pregnant.”

(Family Planning Lead, case vignette 2)

Consequently, concerns about the model's legitimacy and apparent lack of flexibility were raised by some group members and, in the end, most of the projects within the clinical services area continued to be funded.

"I don't know...maybe it wasn't a process that we could tweak as such as we went along, I'm
not sure....the model did feature in our budget discussion, we had a strategy group meeting
where we decided that there were some things that were fixed, such as [name of clinical
service]...but then I think we did say that if there were any flexibility, any flexible elements of
the budget that we should look to using this model.”

(Teenage Pregnancy Strategy Group Co-Chair, case vignette 2)

"I think we have still got to get to the usefulness bit, I found the whole thing really interesting and potentially useful, particularly when we got to the scoring, I think the scoring thing is the basis for future work but we were saying it needs some refinement, we need to do some local refinement really given the anomalies that got thrown up around [name of clinical service], I think we need to do some more local refinement to make it really useful."

(Teenage Pregnancy Strategy Coordinator)

In summary, whilst the models developed during the project review workshops (case vignette 1) became boundary objects in-use by those involved, the models developed during the mapping and decision conference workshops (case vignette 2) did not. In the former, the models developed were useful for group members' interactions within the workshops, enabling them to transfer, translate and transform their perspectives and knowledge about the issues of concern. Furthermore, the models helped members to achieve negotiated agreements that had change consequences for Whitbread's and their partners' work practices, which helped creating a new partnership ethos across different professional groups. On the other hand, in case vignette 2, although successful in assisting group members to work at 
syntactic and semantic boundaries, the models developed failed to engage group members in the negotiation of new meanings and common interests at the pragmatic boundary. In this case the usefulness of the models developed (particularly the portfolio model) was judged against the purposes and intentions of powerful stakeholders and old meanings and current knowledge about clinical services prevailed.

\section{Discussion}

In the previous section, I examined two empirical case vignettes to assess the extent to which the models developed became boundary objects to those involved. In this section I build from this analysis to develop a framework that shows how variations in model affordances enables or constrains the ability of group members to negotiate meanings and common interests that have implications for new knowledge creation and change. I also explore how the research presented here contributes to the negotiation perspective of Soft OR, and the work on evaluating Soft OR interventions. Finally, I provide insights into how Soft OR practitioners can ensure that the models they help create display enough affordances so that they become boundary objects in interaction.

\subsection{The notion of model affordances}

Carlile (2004) argues that boundary objects must have the 'capacity' to represent group members' differences and dependencies, so that they are able to identify and learn about these differences and dependencies in order to negotiate meanings and common interests. However, capacity alone is not sufficient. Models must also enable group members to engage in what Tsoukas (2009) calls 'relational engagement' behaviours that are conducive to open discussion and integrative negotiations, and which generate opportunities for transforming knowledge with action implications. The notions of capacity and relational engagement can be linked to the case vignettes discussed above. In case vignette 1 , the models developed had the capacity to invoke different perspectives, knowledge and interests that were 'at stake' (Carlile 2002), and those involved were able to use that capacity to openly discuss and negotiate new meanings that led to new knowledge and significant changes within the partnership. In case vignette 2, although the models developed did have the capacity to invoke what was at stake, group members were unable to employ that capacity to negotiate new meanings that would have had significant implications for the way the Teenage Pregnancy Strategy Group allocate their budget. Instead, calculative (rather than relational or collaborative) behaviours were displayed to make certain meanings and knowledge nonnegotiable, as in the case of the clinical services.

The case vignettes, though purely illustrative, provide important insights into how these effects are achieved. The vignettes show how a model's affordances -namely, the perceived opportunities for goal-oriented action they offer to group members in interaction- exhibited a degree of variation that was crucial in enabling or constraining (model-supported) meaning negotiations and new knowledge creation, as shown in Figure 2. At least five affordances of models with various types of impact can be identified in the case vignettes:

1) Tangibility: the ability of a model to make its content visible and concrete. This affordance makes domain-relevant knowledge available and tangible, and a source of group discussion and negotiation.

2) Associability: the ability of a model to relate its contents based on shared attributes. This affordance enables those involved to identify knowledge differences and dependencies. 
3) Mutability: the ability of a model to modify its contents on the spot. This affordance allows evolving knowledge-related discussions and negotiations to be reflected in the model incrementally.

4) Traceability: the ability of a model to relate its contents temporally and structurally. This affordance offers opportunities for surveying and assembling knowledge-related discussions and negotiations.

5) Analysibility: the ability of a model to transform inputs into outputs. This affordance enables experimenting with different knowledge-related inputs, and calculating their impact.

\section{PLACE FIGURE 2 ABOUT HERE}

The affordances outlined above, individually or as a bundle, were manifested and perceived differently by those involved in the workshops. In case vignette 1, tangibility was high and, despite their reliance on manual model-based support (i.e. modelling was done in flipcharts), associability, mutability, traceability and analysability were also high. These affordances enabled those involved to adopt a collaborative, rather than calculative, mode of interaction in the negotiation of meanings and interests, leading to new knowledge with action implications. In case vignette 2, all affordances were expected to be high because of the use of computer support for modelling. However, compared to case vignette 1, the models (and, in particular, the portfolio model) did not afford those advocating the clinical services with an opportunity to manage their agenda, resulting in prior knowledge-specific solutions being preferred. As the case vignette quotes suggest, the models were perceived as needing refinement and being inflexible, which can be interpreted as having low tangibility (i.e. lack of 'visibility' of clinical services in the portfolio model) and low mutability (i.e. disagreements about clinical services not reflected in the model), respectively. This may help explain why the modality of engagement in case vignette 2 was calculative rather than collaborative, leading to the same knowledge being reproduced in the ultimate budget allocation adopted by the Teenage Pregnancy Strategy Group.

\subsection{Soft OR as negotiation}

This research makes a contribution to the negotiation perspective advocated by some Soft OR scholars (for a review of this perspective, see Morton, Ackermann, \& Belton, 2003). For example, the boundary object concept can be related to Eden's notion (1992) of models as 'negotiative devices'. According to this view, models are conceptualised as a visible artefact expected to encourage those involved to share, elaborate and negotiate their knowledge, and so change their mind incrementally. Furthermore, effective negotiative devices are always in transition (Ackermann \& Eden, 2011b), in the sense that new aspects of group discussions and negotiations are reflected in changes to the model's content. Thus similarities between the two concepts are evident. However, what this research provides is a way to ground the notion of negotiative devices within a broader framework that distinguishes different boundary spaces for model-supported interactions. Specifically, a boundary object perspective places the role of a model as a negotiative device within the pragmatic boundary space (see Table 1). This implies that for a model to act as a negotiative device, it must be able to act first as a communication device and a learning device at syntactic and semantic boundaries, respectively (see Table 1). In addition, this research provides insights into the types of specific model affordances (tangibility, associability, mutability, traceability, analysibility) that can sustain the role of models as negotiative devices. 
Staying within the negotiation perspective of Soft OR, this research also provides further insight into the role of content and process management in facilitated modelling (Eden, 1990; Franco \& Montibeller, 2010), and their impact on emotional and cognitive commitment (Ackermann \& Eden, 2010; Eden \& Ackermann, 2001). The conventional wisdom is that content and process have a multiplier effect (Eden, 1990) and that good model content increases cognitive commitment, whereas a well managed process facilitates emotional commitment. This research reinforces this view by showing how model content and its use are both needed for creating new knowledge and change. Models become boundary objectives if their content affords those involved to negotiate what is at stake. Thus good model content alone is necessary but not sufficient: if the process of using it constrains (rather than facilitates) negotiation then the model is not a boundary object (or negotiative device) in-use.

\subsection{Implications for Soft OR evaluation research}

The conceptualisation of models as potential boundary objects can shed new light and further extend current research on the impact of Soft OR interventions. Early work tended to emphasize the role of models in facilitating dialogue (e.g. Midgley, 2000; Midgley \& OchoaArias, 2004; Rosenhead \& Mingers, 2001; White, 2009) and the management of meaning (e.g. Eden, Jones, \& Sims, 1983; Eden, Jones, Sims, \& Smithin, 1981) among those involved. The framework presented here contributes towards, and extends, such work, by drawing upon a boundary object perspective to unpack the ways in which models mediate group interactions at different kinds of boundary, including those generated by vested interests.

Empirical research has shown how the affordances of technologies create spaces in which meanings and change can be negotiated (e.g. Kaplan, 2011). As the case vignettes illustrate, models are a type of technology whose affordances (i.e. tangibility, associability, mutability, traceability, analysibilty) have the effect of facilitating or constraining group interactions. Acknowledging the importance of different model affordances provides a 'prescriptive' evaluation framework for Soft OR interventions. Building on the analysis of the case vignettes, the different affordances can be associated with different type of boundary. Typical Soft OR interventions involve working at syntactic, semantic and pragmatic boundaries and thus a model must enable those involved to traverse all three boundaries if it is to become a boundary object in-use. However, some model affordances are likely to be more central than others depending on the type of boundary encountered. For example, when working at the syntactic boundary, tangibility and associability are expected to be critical, whereas mutability, traceability and analysibility are all likely to be central at the semantic and pragmatic boundaries. Therefore, it can be argued that a model may only become a boundary object when its affordances are aligned with the demands of a particular boundary. However, this proposition needs to be further investigated in future research.

\subsection{Implications for Soft OR practice}

The preceding discussion will have made clear that the models developed in Soft OR interventions have multifaceted roles and effects in boundary interactions. In case vignette 1 , the models created were important in enabling effective collaborative problem solving. By contrast, in case vignette 2, models reinforced behaviours that maintained the status quo. This observation is an important counterfoil to the Soft OR literature that highlights the almost uniformly positive role of models in facilitating dialogue, negotiation, knowledge creation and change (e.g. Ackermann, 2012; Franco \& Montibeller, 2010; Mingers, 2011; Mingers \& Rosenhead, 2004). Models may provide an appropriate forum for achieving collaborative 
problem solving. However, their use may also simultaneously signify and reinforce interactions in ways that reflect the particular orientations and interests of those involved. It follows that the role of the operational researcher in facilitating the kind of model-supported interactions conducive to effective problem solving collaboration is, therefore, critical. Furthermore, as suggested above, the effectiveness of the operational researcher's work is likely to be affected by the extent to which the models created are perceived to afford or constrain opportunities for action to those involved.

How can models be perceived to afford rather than constrain opportunities for action during group interactions? Some scholars have persuasively argued that it is the ability to rapidly build visual representations, during the early stages of a model-supported group process, which influences how their potential affordances are perceived by those involved (Ackermann \& Eden, 2011a; Black \& Andersen, 2012; Howick et al., 2006). For example, Black and Andersen (2012) posit that quickly built visual representations become boundary objects that enable group members to rapidly see the potential to surface issues, goals or options that could benefit their position, which can then prompt them to work with opponents to reach a mutually satisfactory way forward. Others, such as Eden (1992), suggest that the use of appropriate computer-supported technology enables models to be manipulated, traced and interactively analysed by those involved, thus becoming transitional (or 'boundary' in the terminology used here) objects in interaction. These scholars highlight the role of particular model affordances (i.e. tangibility, mutability, traceability, analysibility) which are likely to be critical at the syntactic and semantic boundaries. However, as noted in case vignette 2, a problematic scenario may arise when, working at a pragmatic boundary, a powerful group member uses the model to advocate past practices, knowledge or expertise to constrain, rather than afford, action opportunities for other group members. Model-supported group interaction is not a neutral process but a political one, and thus building quick models may just not be enough to traverse the pragmatic boundary. Other considerations need to be taken into account here, as I discuss below.

One aspect that may significantly affect how group members perceive a model's affordances in interaction is the ability to manage model boundaries. Models are the means by which group members declare and choose which knowledge, issues, objectives, or options will be considered when deciding priorities for action, as illustrated in the two case vignettes. Consequently it is central that group members' framings and interests about where the boundaries should be are managed effectively, as this will affect how a model's affordances are perceived by those involved. Managing the process of drawing model boundaries also relates to the need to limit model complexity, as this may constrain the ability to build rapid models (see above), and maintain momentum and focus, in model-supported group interactions. Another aspect that can affect a model's perceived affordances is the ability to sustain appropriate levels of interpretive flexibility in the models created. Research in the sociology of technology treats interpretive flexibility as the capacity of an artefact or model to represent different interpretations (e.g.Bijker, 1987; Doherty, Coombes, \& Loan-Clarke, 2006; Law \& Callon, 1992; Orlikowski, 1992; Pinch \& Bijker, 1987; Sahay \& Robey, 1996), which in the context of models (as examples of a particular form of technology) can be characterised by the 'equivocality' embedded in different model elements (Ackermann \& Eden, 2010; Eden \& Ackermann, 2004; Eden, Ackermann, Bryson, Richardson, \& Andersen, 2009). This research suggests that the presence (or absence) of interpretive flexibility is likely to increase (or constrain) the ability of those involved to reconcile with previous bindings or positions and, consequently, change (or not change) their minds. 
The ability to use models to set agendas (drawing model boundaries), as well as capture and sustain multiple understandings (interpretive flexibility), can help explain why model affordances were perceived differently by those involved in case vignettes 1 and 2. The implication for Soft OR practitioners is to ensure that the models they help create exhibit the required affordances for effective interaction. The use of carefully designed scripts and deliverables, using appropriate technology support can indeed be of significant help in this respect (e.g. Ackermann et al., 2011; Andersen \& Richardson, 1997). However, script and technology alone cannot replace the ability to manage the model-supported interaction process, particularly at the pragmatic boundary. Here, managing model boundaries and sustaining interpretive flexibility are also likely to be important.

\section{Conclusion}

The purpose of this paper has been to rethink soft OR interventions through an examination of models as potential boundary objects. This conceptualisation provided a useful lens to understand that models are not static intervention tools that provide particular instrumental solutions to a problematic situation of concern. Rather, they are focal points around which different perspectives, dependencies, knowledge and interests associated with the situation can be transferred, translated and transformed in interaction. Models become boundary objects because of their affordances, i.e. the possibilities for action they offer to those involved. The boundary object concept shifts our focus to what happens in an intervention when those involved use models to traverse syntactic, semantic and pragmatic boundaries to manage meanings that have consequences for knowledge creation and action. Furthermore, it suggests that when designing and deploying Soft OR interventions, the operational researcher should consider how to support and manage interactions at each of these boundaries.

Obviously there are some limitations in the work presented here that must be acknowledged. First, the case vignettes, although illustrative, do not in any way test the theoretical concepts articulated here. However, the development of the insights discussed in this paper arises out of several empirical studies evaluating the impact of Soft OR interventions in a variety of organisational settings, as well as concepts drawn from the boundary objects literature. The latter provides comprehensive explanations of the role of specific types of artefacts in organisational practices, which I argued are comparable to the role of models in Soft OR interventions. Therefore it can be stated that the theoretical concepts articulated here have been empirically and conceptually refined. Second, this paper has implied the desirability of convergence rather than divergence in Soft OR interventions. However, it is acknowledged that in some interventions divergence is the desired outcome and no decision or action regarding the problem situation is necessarily expected (see, for example, Connell, 2001). Last, as with any work that attempts to incorporate insights from other disciplines and theoretical domains, the effort is not without its rough edges. The arguments presented reduce what is indeed a very complex phenomenon (cf. White, 2009) to a narrow set of theoretical constructs. In addition, they simplify some aspects of Soft OR interventions while stressing others. This effort can be seen as a strength or weakness, depending on how broad an approach to studying Soft OR interventions one takes.

The work described here can inform further research on Soft OR interventions in several ways. As the actual use of models has received scant attention in the Soft OR literature, future empirical research might frame models conceptually as boundary objects in order to analyse how they are used in practice and with what impact. Future research could focus in more detail on what enables or constrains the capacity of a model or the ability of those involved to use it effectively within a Soft OR workshop or throughout a Soft OR 
intervention as a whole. Interesting research questions to explore are, for example: How does a modeller/analyst work towards building the 'right' bundle of model affordances at a particular boundary? During a workshop, at what stage in the modelling process is a boundary encountered or recognised? At what point during a workshop does a model get recognised as a boundary object by those involved, and how? When using models, how do group members draw on model elements to advance particular interests or agendas? Do models become 'participants' in interaction or are they just artefacts to be manipulated by group members? Moreover, collaborative problem solving with multi-organisational groups is particularly challenging, and several scholars highlight the need to focus on goals alignment as an important first step in this setting (e.g. Ackermann, Franco, Gallupe, \& Parent, 2005; Franco, 2008; Huxham, 1996). When working with multi-organisational groups in a workshop setting, how do members draw on their domain-specific knowledge and authority to strengthen their status and influence at the expense of creating shared meanings and negotiating common interests? Does a modelling focus on goals offer an effective approach to models becoming boundary objects in multi-organisational settings? More generally, how does context (single- versus multi-organisational) affect the ability of models to become boundary objects in group interactions?

To explore these questions it is crucial that empirical studies of Soft OR interventions must include not just details of the models themselves but, equally important, the social interaction context in which the models are produced and that they also produce through their use. This means being able to capture and examine model-supported group interactions and conversational exchanges (cf. Franco, 2006; Franco \& Rouwette, 2011; Horlick-Jones \& Rosenhead, 2007), which would allow us to explore the various practices and behaviours group members perform, and with what effects.

Acknowledgements: I am indebted to Paul Keys and Thanos Papadopoulos, who gave me feedback on earlier drafts of this paper. The arguments developed in this paper have profited immensely from earlier discussions with Ashley Carreras, Mike Cushman, Giles Hindle, Gerald Midgley, Gilberto Montibeller, Etienne Rouwette, Richard Vidgen and Leroy White. The responsibility for presenting them in this way is, however, entirely mine.

References

Ackermann, F. 2012. Problem structuring methods 'in the Dock': Arguing the case for Soft OR. European Journal of Operational Research, 219(3): 652-658.

Ackermann, F., Andersen, D. F., Eden, C., \& Richardson, G. P. 2011. Scriptsmap: a tool for designing multi-method policy-making workshops. OMEGA: The International Journal of Management Science:, 39(4): 427-434.

Ackermann, F., \& Eden, C. 2010. Strategic Options Development and Analysis. In M. Reynolds, \& S. Holwell (Eds.), Systems Approaches to Managing Change: A Practical Guide: 135-190. London: Springer.

Ackermann, F., \& Eden, C. 2011a. Making Strategy: Mapping out strategic success (2nd ed.). London: Sage.

Ackermann, F., \& Eden, C. 2011b. Negotiation in Strategy Making Teams: Group Support Systems and the Process of Cognitive Change. Group Decision and Negotiation, 20: 293-314.

Ackermann, F., Franco, L. A., Gallupe, B., \& Parent, M. 2005. Group Support Systems for Multi-organizational Collaboration: Reflections on process and content. Group Decision and Negotiation, 14(4): 307-331. 
Andersen, D., \& Richardson, G. 1997. Scripts for Group Model Building. System Dynamics Review, 13(2): 107-130.

Barley, W. C., Leonardi, P. M., \& Bailey, D. E. 2012. Engineering objects for collaboration: Strategies of ambiguity and clarity at knowledge boundaries. Human Communication Research, 38: 280-308.

Bechky, B. A. 2003a. Object lessons: Workplace artefacts as representations of occupational jurisdiction. American Journal of Scoiology, 109: 720-752.

Bechky, B. A. 2003b. Sharing meaning across occupational communities: The transformation of understanding on a production floor. Organization Science, 14(3): 312-330.

Bijker, W. 1987. The social construction of bakelite: Towards a theory of invention. In W. Bijker, T. Hughes, \& T. Pinch (Eds.), The Social Construction of Technological Systems: 159-187. Cambridge, MA: MIT Press.

Black, L. J., \& Andersen, D. F. 2012. Using Visual Representations as Boundary Objects to Resolve Conflict in Collaborative Model-Building Approaches. Systems Research and Behavioral Science, 29(2): 194-208.

Boland, R. J., \& Tenkasi, R. V. 1995. Perspective making and perspective taking in communities of knowing. Organization Science, 6(4): 350-372.

Burnes, B., \& Cooke, B. 2012. The past, present and future of organization development: Taking the long view. Human Relations, 65(11): 1395-1429.

Carlile, R. P. 2002. A pragmatic view of knowledge and boundaries: Boundary objects in new product development. Organization Science, 13: 442-455.

Carlile, R. P. 2004. Transferring, translating, and transforming: An integrative framework for managing knowledge across boundaries. Organization Science, 15: 555-568.

Carlile, R. P., \& Rebentisch, E. S. 2003. Into the Black Box: The Knowledge Transformation Cycle. Management Science, 49(9): 1180-1195.

Connaughton, J. N., \& Green, S. D. 1996. A Client.s Guide to Value Management in Construction. London: CIRIA.

Connell, N. 2001. Evaluating Soft OR: some reflections on an apparently 'unsuccessful' implementation using a Soft Systems Methodology (SSM) based approach. Journal of Operational Research Society, 52(1): 150-160.

Doherty, N., Coombes, C. R., \& Loan-Clarke, J. 2006. A re-conceptualization of the interpretive flexibility of information technologies: redressing the balance between the social and technical European Journal of Information Systems, 15: 569-582.

Dougherty, D. 2002. Grounded theory building: Some principles and practices. In J. A. C. Baum (Ed.), Companion to Organizations: 849-867. Oxford: Blackwell Publishers.

Eden, C. 1978. Operational Research and Organization Development. Human Relations, 31(8): 657-674.

Eden, C. 1988. Cognitive Mapping: a review. European Journal of Operational Research, 36(1): 1-13.

Eden, C. 1990. The Unfolding Nature of Group Decision Support: two dimensions of skill. In C. Eden, \& J. Radford (Eds.), Tackling Strategic Problems: the role of group decision support 48-52. London: Sage.

Eden, C. 1992. A Framework for Thinking About Group Decision Support Systems. Group Decision and Negotiation, 1: 199-218.

Eden, C. 2004. Analyzing Cognitive Maps to Help Structure Issues or Problems. European Journal of Operational Research, 159(3): 673-686.

Eden, C., \& Ackermann, F. 2001. Group Decision and Negotiation in Strategy Making. Group Decision and Negotiation, 10(2): 119-140. 
Eden, C., \& Ackermann, F. 2004. Use of 'Soft OR' Models by Clients: what do they want from them? In M. Pidd (Ed.), Systems Modelling: theory and practice: 146-163. Chichester: Wiley.

Eden, C., Ackermann, F., Bryson, J., Richardson, G., \& Andersen, D. 2009. Integrating modes of policy analysis and strategic management practice: Requisite elements and dilemmas. Journal of the Operational Research Society, 60(1): 2-13.

Eisenhardt, K. M. 1989. Building Theories from Case Study Research. Academy of Management Review, 14(4): 532-550.

Eisenhardt, K. M., \& Graebner, M. E. 2007. Theory building from case studies: Opportunities and challenges. Academy of Management Journal, 50(1): 25-32.

Franco, L. A. 2006. Forms of Conversation and Problem Structuring Methods: a conceptual development. Journal of the Operational Research Society, 57(7): 813-821.

Franco, L. A. 2007. Assessing the Impact of Problem Structuring Methods in Multiorganisational Settings: an empirical investigation. Journal of the Operational Research Society, 58(6): 760-768.

Franco, L. A. 2008. Facilitating Collaboration with Problem Structuring Methods: a case of an inter-organisational construction partnership. Group Decision and Negotiation, 17(4): 267-286.

Franco, L. A. 2009. Problem Structuring Methods as Intervention Tools: reflections from their use with multi-organizational teams. OMEGA: The International Journal of Management Science, 37(1): 193-203.

Franco, L. A., Cushman, M., \& Rosenhead, J. 2004. Project Review and Learning in the UK Construction Industry: Embedding a Problem Structuring Method within a partnership context. European Journal of Operational Research, 152(3): 586-601.

Franco, L. A., \& Lord, E. 2011. Understanding Multi-Methodology: Evaluating the perceived impact of mixing methods for group budgetary decisions. OMEGA: The International Journal of Management Science, 39(3): 362-372.

Franco, L. A., \& Montibeller, G. 2010. Facilitated Modelling in Operational Research (Invited Review). European Journal of Operational Research, 205(3): 489-500.

Franco, L. A., \& Rouwette, E. A. J. A. 2011. Decision Development in Facilitated Modelling Workshops European Journal of Operational Research, 212(1): 164-178.

Friend, J., \& Hickling, A. 2005. Planning Under Pressure: the strategic choice approach (3rd ed.): Elsevier.

Gibson, J. J. 1986. The Ecological Approach to Visual Perception. Hillsdale, NJ: Lawrence Erlbaum Associates.

Henderson, K. 1991. Flexible Sketches and Inflexible Data Bases: Visual Communication, Conscription Devices, and Boundary Objects in Design Engineering. Science, Technology and Human Values, 16(4): 448-473.

Horlick-Jones, T., \& Rosenhead, J. 2007. The Uses of Observation: combining problem structuring methods and ethnography. 58, 5(588-601).

Howick, S., \& Ackermann, F. 2011. Mixing OR methods in practice: Past, present and future directions. European Journal of Operational Research, 215(3): 503-511.

Howick, S., Ackermann, F., \& Andersen, D. 2006. Linking event thinking with structural thinking: methods to improve client value in projects. System Dynamics Review, 22(2): 113-140.

Hutchby, I. 2001. Technologies, Texts and Affordances. Sociology, 35(2): 441-456.

Huxham, C. 1996. Group Decision Support for Collaboration. In C. Huxham (Ed.), Creating Collaborative Advantage: 141-151. London: Sage.

Jarzabkowski, P., Spee, A. P., \& Smets, M. 2013. Material artifacts: Practices for doing strategy with stuff. European Management Journal, 31(1): 41-54. 
Kaplan, S. 2011. Strategy and PowerPoint: An inquiry into the epistemic culture and machinery of strategy making. Organization Science, 22(2): 320-346.

Keys, P. 2007a. Knowledge Work, Design Science and Problem Structuring Methodologies. Systems Research and Behavioral Science, 24: 523-535.

Keys, P. 2007b. Reducing the Process Lacuna in Operational Research by Taking a Knowledge Work Perspective. Systems Research and Behavioral Science, 24: 285296.

Law, J., \& Callon, M. 1992. The Life and Death of an Aircraft: A network analysis of technical change In W. Bijker, \& J. Law (Eds.), Shaping Technology/Building Society: 21-52. Cambridge, MA: MIT Press.

Levina, N. 2005. Collaborating on multiparty information systems development projects: A collective reflection-in-action view. Information Systems Research, 16(2): 109-130.

Levina, N., \& Vaast, E. 2005. The Emergence of Boundary Spanning Competence in Practice: Implications for Implementation and Use of Information Systems. MIS Quarterly, 29(2): 335-363.

Mingers, J. 2011. Soft OR comes of age -But not everywhere! OMEGA: The International Journal of Management Science, 39(6): 729-741.

Mingers, J., \& Rosenhead, J. 2004. Problem Structuring Methods in Action. European Journal of Operational Research, 152(3): 530-554.

Morton, A., Ackermann, F., \& Belton, V. 2003. Technology-driven and Model-driven Approaches to Group Decision Support: focus, research philosophy and key concepts. European Journal of Information Systems, 12(2): 110-126.

Munro, I., \& Mingers, J. 2002. The Use of Multimethodology in Practice: results from a survey of practitioners. Journal of Operational Research Society, 53(4): 369-378.

Nicolini, D., Mengis, J., \& Swan, J. 2012. Understanding the Role of Objects in CrossDisciplinary Collaboration. Organization Science, 23(3): 612-629.

O'Brien, F. 2011. Supporting the Strategyc Process: A survey of UK OR/MS Practitioners. Journal of the Operational Research Society (forthcoming).

Orlikowski, W. J. 1992. The duality of technology: Rethinking the concept of technology in organizations. Organization Science, 3(2): 398-427.

Pawlowski, S. D., \& Robey, D. 2004. Bridging user organizations: Knowledge brokering and the work of information technology professionals. MIS Quarterly, 28(4): 645-672.

Phillips, L. 2007. Decision Conferencing. In W. Edwards, R. Miles Jr, \& D. von Winterfeldt (Eds.), Advances in Decision Analysis: from foundations to applications: 375-399. New York: Cambridge University Press.

Phillips, L., \& Bana e Costa, C. A. 2007. Transparent Prioritisation, Budgeting, and Resource Allocation with Multi-Criteria Decision Analysis and Decision Conferencing. Annals of Operations Research, 154(1): 51-68.

Pidd, M. 2003. Tools for Thinking: modelling in management science. Chichester: Wiley.

Pidd, M. 2010. Why modelling and model use matter. Journal of the Operational Research Society, 61(1): 14-24.

Pinch, T., \& Bijker, W. 1987. The social construction of facts and artefacts: on how the sociology of science and sociology of technology might benefit each other. In W. Bijker, P. Hughes, \& T. Pinch (Eds.), The Social Construction of Technological Systems: 159-187. Cabridge, MA: MIT Press.

Rouwette, E. A. J. A., Vennix, J. A. M., \& van Mullekom, T. 2002. Group Model Building Effectiveness: a review of assessment studies. System Dynamics Review, 18(1): 5-45.

Sahay, S., \& Robey, D. 1996. Organizational context, social interpretation, and the implementation and consequences of geographic information systems. Accounting, Management and Information Technology, 6(4): 255-282. 
Salo, A., Keisler, J., \& Morton, A. (Eds.). 2011. Advances in Portfolio Decision Analysis: Improved methods for resource allocation. Berlin: Springer.

SEU. 1999. Bridging the Gap: new opportunities for 16-18 year olds not in employment, education or training. London: The Stationary Office.

Shaw, D., Ackermann, F., \& Eden, C. 2003. Approaches to Sharing Knowledge in Group Problem Structuring. Journal of the Operational Research Society, 54(9): 936-948.

Star, S. L. 1989. The structure of ill-structured solutions: Boundary objects and heterogeneous distributed problem solving. In M. Huhns, \& L. Gasser (Eds.), Readings in Distributed Artificial Intelligence. Menlo Park, CA: Morgan Kaufman.

Star, S. L. 2010. This is not a boundary object: Reflections on the origin of a concept. Science, Technology and Human Values, 35(5): 601-617.

Star, S. L., \& Griesemer, R., J. 1989. Institutional Ecology, 'Translations', and Boundary Objects: amateurs and professionals in Berkeley's Museum of Vertebrae Zoology. Social Studies of Science, 19: 387-420.

Strauss, A., \& Corbin, J. 1998. Basics of Qualitative Research: techniques and procedures for developing grounded theory. London: Sage.

Tsoukas, H. 2009. A Dialogical Approach to the Creation of New Knowledge in Organizations. Organization Science, 20(6): 941-957.

White, L. 2009. Understanding Problem Structuring Methods Interventions. European Journal of Operational Research, 99(3): 823-833.

Yanow, D., \& Schwarz-Shea, P. 2006. Interpretation and Method: Empirical Research Methods and the Interpretive Turn. New York: M. E. Sharpe.

Zagonel, A. A. 2002. Model conceptualization in group model building: a review of the literature exploring the tension between representing reality and negotiating a social order. Paper presented at the International Conference of the System Dynamics Society, Palermo. 
Table 1: Model roles and effects at syntactic, semantic, and pragmatic boundaries -based on Carlile (2002; 2004)

\begin{tabular}{|c|c|c|}
\hline $\begin{array}{l}\text { Type of boundary } \\
\text { faced }\end{array}$ & Model role & Model effects \\
\hline $\begin{array}{l}\text { Syntactic boundary: } \\
\text { Perceived nature of } \\
\text { problem situation } \\
\text { means that differences } \\
\text { and dependencies are } \\
\text { relatively known or } \\
\text { clear. }\end{array}$ & $\begin{array}{l}\text { Transferring or } \\
\text { communicating } \\
\text { perspectives and } \\
\text { knowledge between those } \\
\text { involved. }\end{array}$ & $\begin{array}{l}\text { A shared language is developed } \\
\text { that is sufficient to specify } \\
\text { differences and dependencies, } \\
\text { and generate a way forward } \\
\text { regarding the problem. }\end{array}$ \\
\hline $\begin{array}{l}\text { Semantic boundary: } \\
\text { Perceived nature of } \\
\text { problem situation } \\
\text { generates some } \\
\text { differences and } \\
\text { dependencies that are } \\
\text { unclear. }\end{array}$ & $\begin{array}{l}\text { Translating perspectives } \\
\text { and knowledge between } \\
\text { those involved }\end{array}$ & $\begin{array}{l}\text { Shared meanings are created that } \\
\text { are sufficient to specify and } \\
\text { learn about differences and } \\
\text { dependencies, and generate a } \\
\text { way forward regarding the } \\
\text { problem. }\end{array}$ \\
\hline $\begin{array}{l}\text { Pragmatic boundary: } \\
\text { Perceived nature of } \\
\text { problem situation } \\
\text { generates vested } \\
\text { interests. }\end{array}$ & $\begin{array}{l}\text { Transforming } \\
\text { perspectives, knowledge } \\
\text { and interests between } \\
\text { those involved }\end{array}$ & $\begin{array}{l}\text { Common interests are developed } \\
\text { that are sufficient to resolve the } \\
\text { anticipated implications of } \\
\text { differences and dependencies, } \\
\text { and generate new knowledge } \\
\text { and a way forward regarding the } \\
\text { problem. }\end{array}$ \\
\hline
\end{tabular}


Accepted for publication in the European Journal of Operational Research

Figure 1: Group discussion structured around an evolving decision graph (case vignette 1)

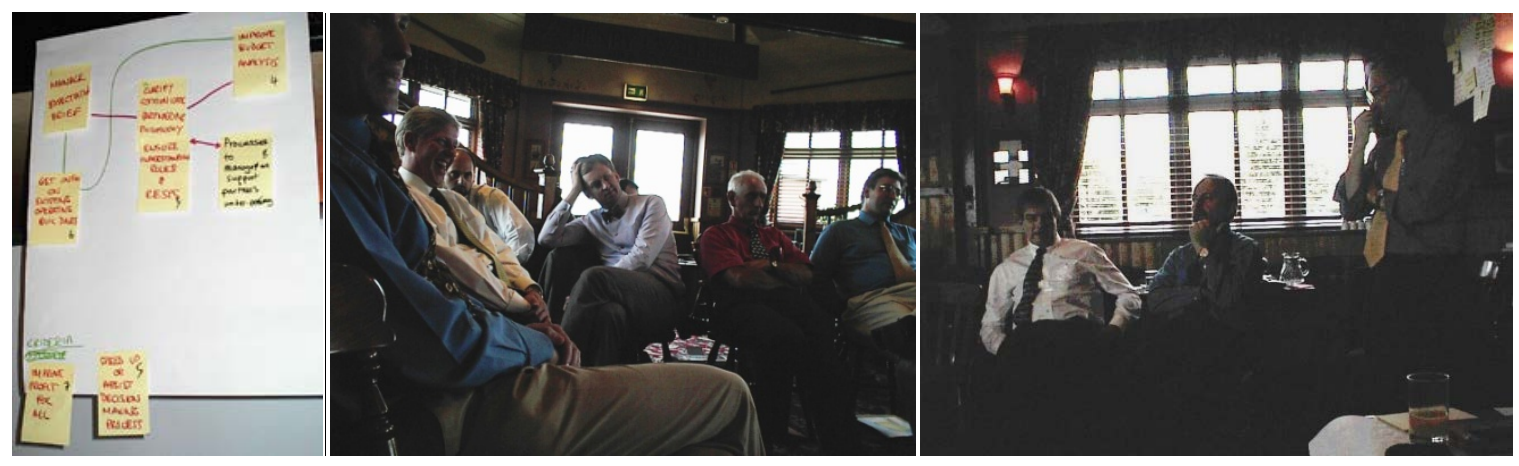


Figure 2: The relationship between model affordances, model-supported meaning negotiation, and novelty of knowledge

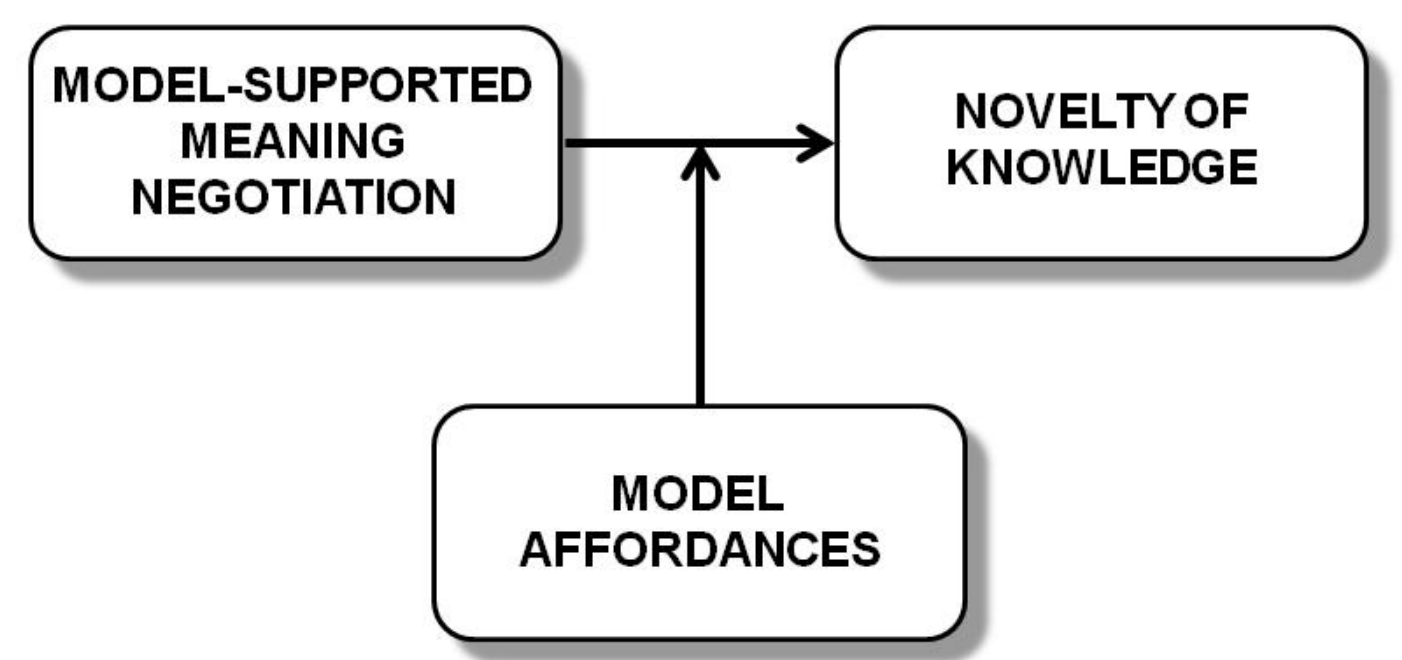

